\title{
Limited accessibility to surface area generated by thermal pretreatment of electrodes reduces its impact on redox flow battery performance
}

Katharine V. Greco ${ }^{\mathrm{a}, \mathrm{b}}$, Jude K. Bonesteel ${ }^{\mathrm{b}}$, Nicolas Chanut ${ }^{\mathrm{c}}$, Charles Tai-Chieh Wan ${ }^{\mathrm{a}, \mathrm{b}}$, Yet-Ming Chiang $^{\mathrm{d}}$, Fikile R. Brushett ${ }^{\mathrm{a}, \mathrm{b},{ }^{*}}$

a Joint Center for Energy Storage Research, Massachusetts Institute of Technology, Cambridge MA 02139

${ }_{b} \quad$ Department of Chemical Engineering, Massachusetts Institute of Technology, Cambridge, MA 02139

c MultiScale Materials Science for Energy and Environment, CNRS/MIT/Aix-Marseille University Joint Laboratory at Massachusetts Institute of Technology, Cambridge, MA 02139

d Department of Material Science and Engineering, Massachusetts Institute of Technology, Cambridge, MA 02139

* Corresponding author.E-mail address: brushett@,mit.edu

\section{S1. Scanning electron microscopy (SEM)}

SEM images of electrodes pretreated at $450{ }^{\circ} \mathrm{C}$ at each treatment time are shown in Figure S1. The images show that qualitatively there is little difference in electrode morphology, with some surface roughness appearing at $12 \mathrm{~h}$ and $24 \mathrm{~h}$. The trends observed in these SEMs are representative of the other pretreated electrodes in this work.

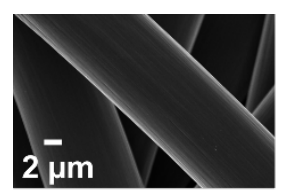

Pristine

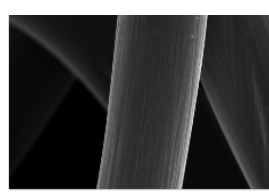

$0.5 \mathrm{~h}$

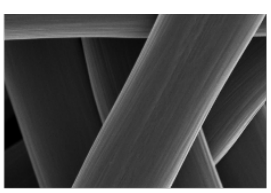

$3 \mathrm{~h}$

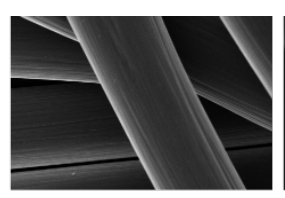

$6 \mathrm{~h}$

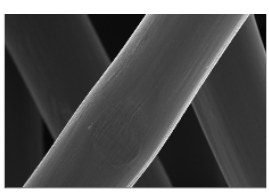

$12 \mathrm{~h}$

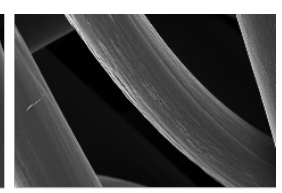

$24 \mathrm{~h}$

Figure S1: SEM images at 10,000× magnification of electrodes treated at $450{ }^{\circ} \mathrm{C}$ as a function of pretreatment time from left to right.

\section{S2. Areal density}

Areal density of the Freudenberg H23 electrodes was calculated by measuring the weight (g) of the electrode $(n=6)$ and dividing the average weight by electrode area $\left(2.24 \mathrm{~cm}^{2}\right)$. The areal density as a function of pretreatment time and temperature is shown in Figure S2. We found that the areal density of electrodes at $400{ }^{\circ} \mathrm{C}$ remains constant across all pretreatment times, while the areal density for electrodes treated at 450 and $500{ }^{\circ} \mathrm{C}$ decreases as a function of pretreatment time. For $450{ }^{\circ} \mathrm{C}$, areal density decreases slightly before decreasing significantly at the longest $(24 \mathrm{~h})$ treatment time. Note that this change in areal density does not impact the reported polarization results in Figure 5-specifically, current normalization by electrode weight rather than electrode 


\section{Supporting Information}

area yields similar trends. Areal density of electrodes treated at $500{ }^{\circ} \mathrm{C}$ quickly decreases as pretreatment temperature increases.

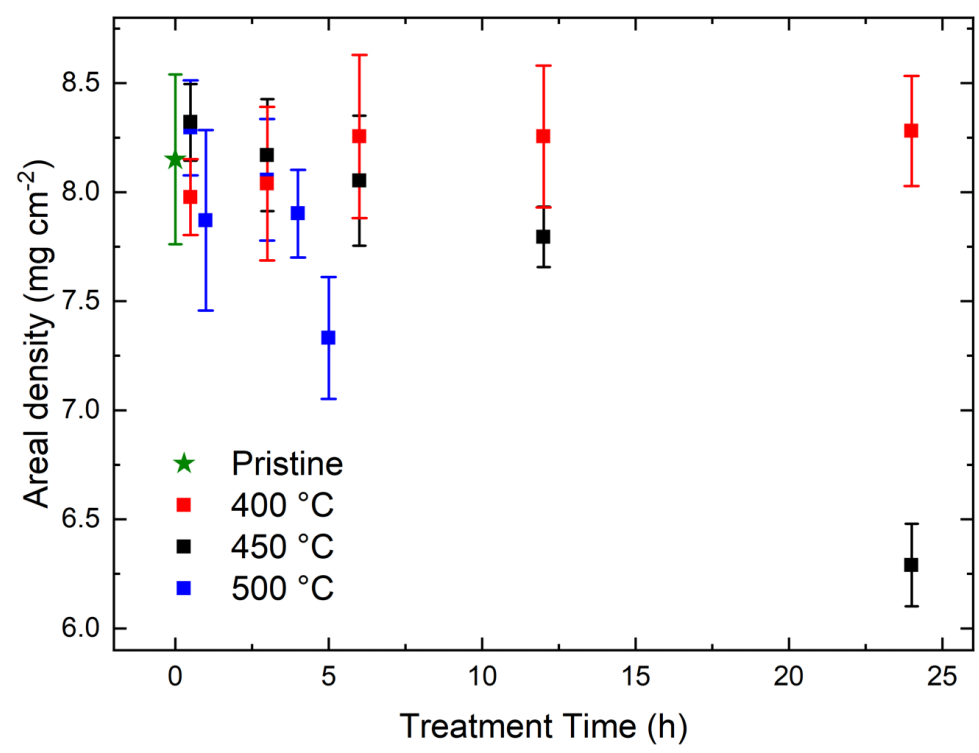

Figure S2 - Areal density of electrodes as a function of pretreatment time.

\section{S3. External water droplet apparent contact angle}

To estimate the wetting properties of thermally treated samples, qualitative external contact angle measurements of water droplets and acetonitrile droplets $(\sim 2 \mu \mathrm{L})$ were performed $(n=3)$. Water droplets on pristine electrodes have an average contact angle of $117 \pm 4^{\circ}$, whereas all heat-treated materials immediately imbibe water (Figure S3). All samples, pristine and heat-treated, immediately imbibe acetonitrile.

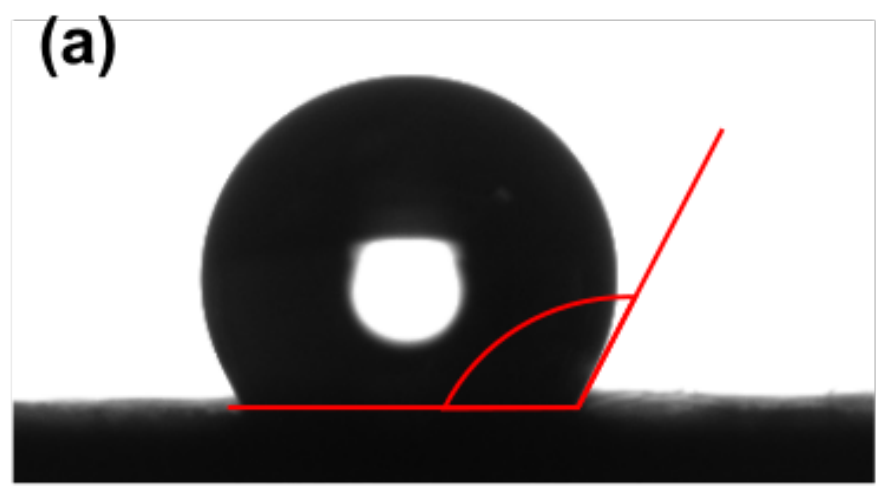

\section{(b)}

Figure S3 - Representative image of external contact angle for (a) pristine and (b) heat-treated electrodes. The droplet in (a) is DI water. 


\section{S4. Representative CV curves and curve fitting procedure}

The linear relationship between current and scan rate was utilized to calculate electrode capacitance. Scan rates used were 5, 10, 20,50,100, and $200 \mathrm{mV} \mathrm{s}^{-1}$ and the cell voltage range was from -0.3 to $0.3 \mathrm{~V}$ (Figure S4a). The current density was determined by averaging the magnitudes of the positive current from the positive voltage sweep and negative current from the negative voltage sweep at a chosen cell voltage of $0 \mathrm{~V}$. This average current density was plotted as a function of scan rate in Figure $\mathbf{S 4 b}$, and a linear fit was used to determine the slope (i.e., capacitance). The ECSA was then calculated by subtracting the blank-cell capacitance (measured in a flow cell without electrodes) and normalizing by the specific capacitance of glassy carbon: $C_{\mathrm{s}, \mathrm{gc}}$ (aqueous) $\approx 0.23 \mathrm{~F} \mathrm{~m}^{-2}$ in $0.5 \mathrm{M} \mathrm{H}_{2} \mathrm{SO}_{4} /$ water (aqueous electrolyte) ${ }^{1}$ and $C_{\mathrm{s}, \mathrm{gc}}($ nonaqueous $) \approx 0.18 \mathrm{~F} \mathrm{~m}^{-2}$ in $0.25 \mathrm{M} \mathrm{TEABF}_{4} /$ acetonitrile (nonaqueous electrolyte). ${ }^{2}$ Each experiment was repeated once. Representative data and linear fit for electrodes pretreated at 450 ${ }^{\circ} \mathrm{C}$ for $12 \mathrm{~h}$ are shown in Figure $\mathbf{S 4}$.
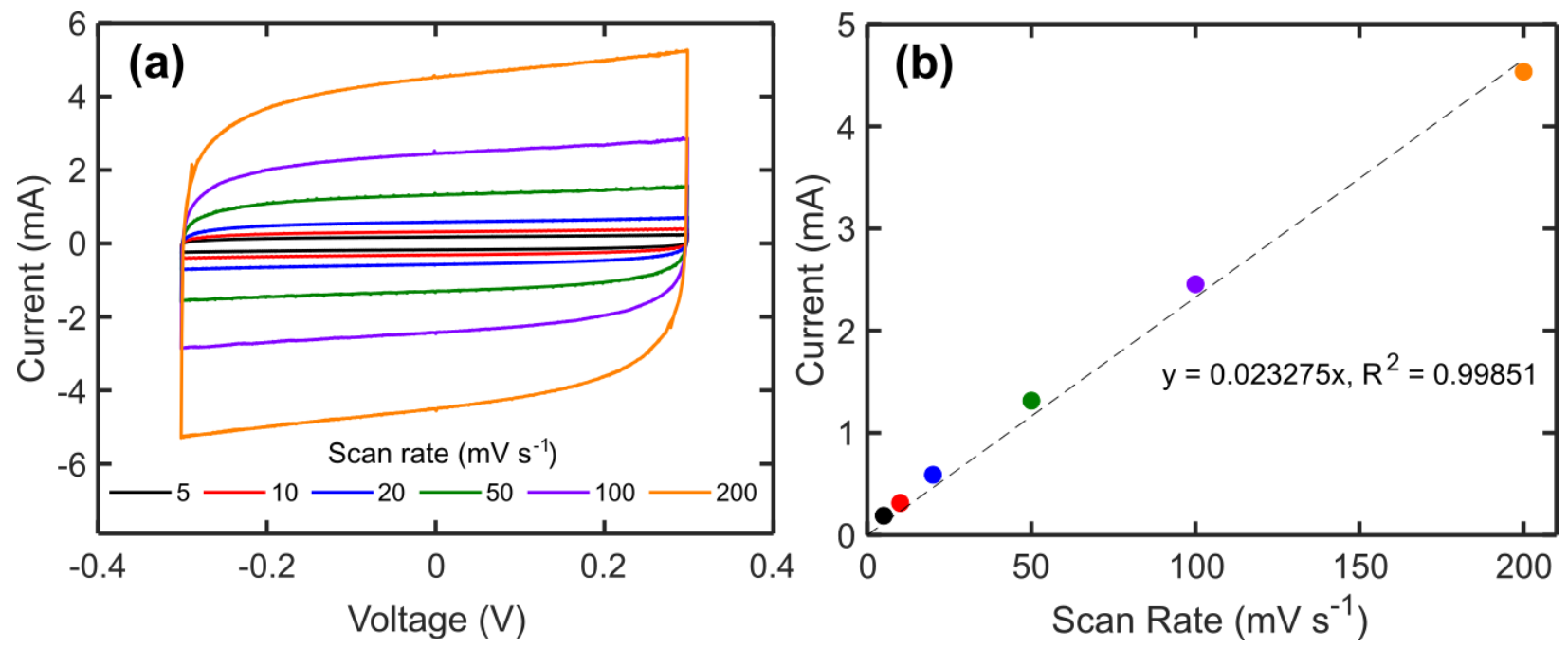

Figure S4 - (a) Representative CV curve and (b) curve fitting procedure to calculate electrode capacitance from $\mathrm{CV}$ in $1 \mathrm{M} \mathrm{TEABF}_{4}$ for electrodes treated at $450{ }^{\circ} \mathrm{C}$ for 12 hours.

The slope of the current vs. scan rate plot in Figure $\mathbf{S 4 b}$ is the capacitance of the system: 0.023 F. The average blank cell capacitance (cell without electrodes) was measured to be $0.0063 \mathrm{~F}$, thus the electrode capacitance is $0.017 \mathrm{~F}$. We normalize the electrode capacitance with the average mass of the electrodes (Freudenberg $\mathrm{H} 23$ electrode treated at $450{ }^{\circ} \mathrm{C}$ for $12 \mathrm{~h}$ have an average areal density of $7.8 \mathrm{mg} \mathrm{cm}^{-2}$, and the active area is $2.55 \mathrm{~cm}^{2}$, thus the average electrode mass is 0.020 g) to obtain the capacitance per gram, $0.85 \mathrm{~F} \mathrm{~g}^{-1}$. Since these data were collected in nonaqueous 1 
$\mathrm{M} \mathrm{TEABF} 4$, we divide the capacitance per gram by $C_{\mathrm{s}, \mathrm{gc}}$ (nonaqueous) $\approx 0.18 \mathrm{~F} \mathrm{~m}^{-2}$ to obtain an ECSA of $4.7 \mathrm{~m}^{2} \mathrm{~g}^{-1}$. Note that each experiment was repeated twice.

\section{S5. Single electrolyte flow cell configuration}

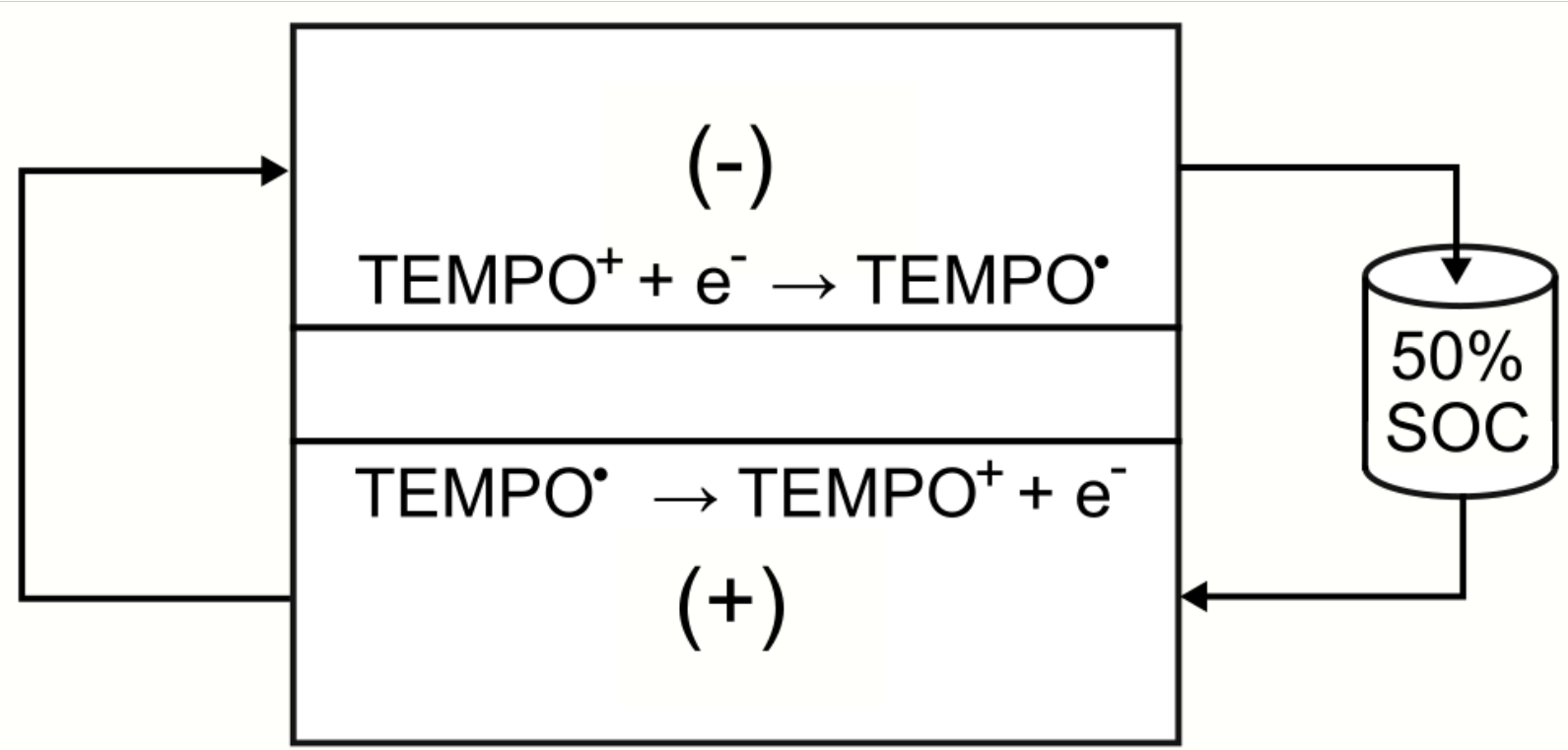

Figure S5: Schematic of the single electrolyte flow cell configuration employed in this work. The

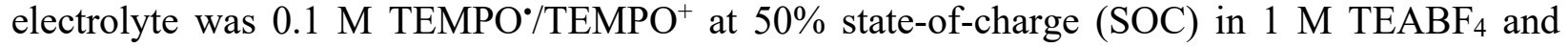
acetonitrile; on the positive side, the TEMPO ${ }^{*}$ is oxidized to $\mathrm{TEMPO}^{+}$, while on the negative side the $\mathrm{TEMPO}^{+}$is reduced to TEMPO', thus maintaining the electrolyte at $50 \%$ SOC for the duration of testing and mitigating crossover effects.

\section{S6. Convection-reaction model formulation and results}

As stated in the main text, the model formulation depends on the assumption that the electrodescale Péclet number $(\mathrm{Pe}$, the convective mass transport rate compared to the diffusive mass transport rate) is large $(P e>>1)$, and that the boundary layer effect along the reaction surface is negligible, as the electrode-scale Damköhler number ( $D a$, ratio of the reaction rate to the diffusive mass transport rate) is small ( $D a<<1)$. To justify these assumptions, we show the order-ofmagnitude approximations for each variable used in the scaling analysis in Table S1. 
Table S1 - Order of magnitude approximations of the physical quantities used in the scaling analysis of transport within the electrode system, as well as resulting scaling of $P e$ and $D a$. A justification is provided for each property.

\begin{tabular}{|c|c|c|}
\hline Property & $\begin{array}{l}\text { Order of } \\
\text { magnitude }\end{array}$ & Justification \\
\hline $\begin{array}{l}\text { Superficial } \\
\text { velocity, } u\left(\mathrm{~m} \mathrm{~s}^{-1}\right)\end{array}$ & & $\begin{array}{l}\text { Range of velocities typically used in flow cell experiments; } \\
\text { calculated from pump volumetric flow rate and the } \\
\text { dimensions of the flow field and electrode. }{ }^{3}\end{array}$ \\
\hline $\begin{array}{l}\text { Length of flow } \\
\text { path, } L(\mathrm{~m})\end{array}$ & $10^{-4}$ & $\begin{array}{l}\text { The flow path is assumed to be the slab volume divided by } \\
\text { surface area. Electrode dimensions are } 0.017 \mathrm{~m} \times 0.015 \mathrm{~m} \times \\
0.00021 \mathrm{~m} \text {. }\end{array}$ \\
\hline $\begin{array}{l}\text { Diffusivity of } \\
\text { reactant, } D\left(\mathrm{~m}^{2} \mathrm{~s}^{-1}\right)\end{array}$ & $10^{-9}$ & $\begin{array}{l}\text { Experimentally measured diffusivity for the electrochemical } \\
\text { species in this work. }{ }^{4}\end{array}$ \\
\hline $\begin{array}{l}\text { Microscopic } \\
\text { length scale, } l(\mathrm{~m})\end{array}$ & $10^{-6}$ & $\begin{array}{l}\text { Square root of electrode permeability, derived } \\
\text { experimentally from the Darcy-Forchheimer equation. }{ }^{4}\end{array}$ \\
\hline $\begin{array}{l}\text { Effective } \\
\text { homogeneous rate } \\
\text { constant, } k\left(\mathrm{~s}^{-1}\right)\end{array}$ & $10^{-5}-10^{2}$ & $\begin{array}{l}\text { Calculated with electrode surface area and heterogeneous } \\
\text { standard rate constant } k^{0} \text {, which was varied from } 10^{-10} \text { to } 10^{-} \\
{ }^{6} \mathrm{~m} \mathrm{~s}^{-1} \text {. Typical standard rate constants of redox molecules } \\
\text { used in RFB systems vary from } 10^{-10} \mathrm{~m} \mathrm{~s}^{-1} \text { for slow systems } \\
\text { (i.e., vanadium) })^{5} \text { to } 10^{-3} \mathrm{~m} \mathrm{~s}^{-1} \text { for fast systems } \\
\text { (i.e., TEMPO.) }{ }^{6} \text { However, for standard rate constants above } \\
10^{-6} \mathrm{~m} \mathrm{~s}^{-1} \text { the scaling of } D a \text { does not meet the required criteria } \\
\text { of } D a<<1 \text {, thus we limit our study to rate constants of } 10^{-6} \\
\mathrm{~m} \mathrm{~s}^{-1} \text { or less. The standard rate constant was normalized by } \\
\text { the volumetric surface area internal to the slab (calculated } \\
\left.\text { with ECSA (varied from } 0.1-100 \mathrm{~m}^{2} \mathrm{~g}^{-1}\right) \text { multiplied by the } \\
\text { density of the electrode material }\left(\rho=2 \times 10^{6} \mathrm{~g} \mathrm{~m}^{-3} \text {, measured }\right. \\
\text { experimentally). }\end{array}$ \\
\hline Péclet number, $P e$ & $10-10^{6}$ & $P e=\frac{u L}{D}$ \\
\hline $\begin{array}{l}\text { Damköhler } \\
\text { number, } D a\end{array}$ & $10^{-7}-10^{-1}$ & $D a=k \frac{l^{2}}{D}$ \\
\hline
\end{tabular}


To investigate the effect of ECSA on concentration profile within the electrode slab, we plot dimensionless concentration as a function of position within the slab at fixed standard kinetic rate constant and interstitial velocity (Figure S6a). We find that the active species concentration exponentially decays along the flow path, and that there is greater consumption of active species at larger ECSA. To further understand the impact of kinetics and transport on electrode performance, we present the calculated effectiveness factor, which is the rate of reaction normalized by the rate of reaction if the entirety of the internal surface of the electrode were exposed to the bulk concentration, as a function of the dimensionless parameter $\mathrm{kL} / \mathrm{u}$, which is the ratio of the reaction rate to the convective transport rate (Figure $\mathbf{S 6 b}$ ). We find that increasing standard rate constant decreases the effectiveness factor, as faster active species consumption causes diminishing concentration through the slab. Similarly, we find that increasing interstitial velocity increases the effectiveness factor, as the active species is more quickly replenished and thus concentration gradients through the electrode are minimized. Ideally, as rate constant increases (either through increases in ECSA or standard rate constant), transport rates would increase to balance the increased rate of consumption of active species.
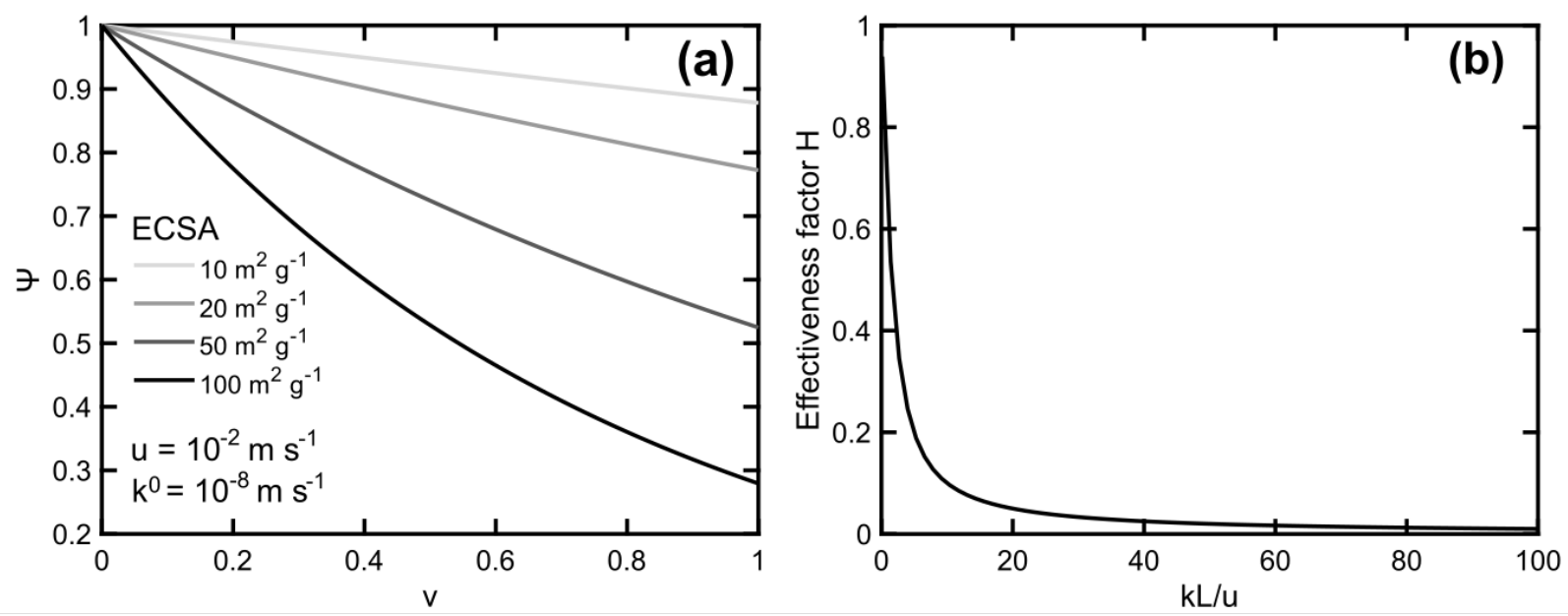

Figure S6 - (a) Dimensionless concentration profile over the length of the electrode. Standard rate constant was set to $10^{-8} \mathrm{~m} \mathrm{~s}^{-1}$, interstitial velocity was set to $10^{-2} \mathrm{~m} \mathrm{~s}^{-1}$, and ECSA was varied from 10 to $100 \mathrm{~m}^{2} \mathrm{~g}^{-1}$. (b) Effectiveness factor as a function of dimensionless parameter $k L / u$. Effectiveness factor diminishes quickly as this parameter increases, reflecting the concentration gradients that form due to fast kinetics and/or diminished interstitial velocity. 


\section{S7. Mercury Intrusion Porosimetry (MIP)}

Samples were sent to Particle Testing Authority (Norcross, GA) to characterize the pore size distribution (PSD) of electrodes at larger pore sizes (up to $350 \mu \mathrm{m}$ ). Figure S7 shows the majority of the porosity comes from pores with diameters less than $10 \mathrm{~nm}$, thus confirming BET as an appropriate method for analyzing the surface area and morphology. Specifically, we note that the shape of the PSD derived from MIP differs from that of gas adsorption. This is likely due to the "ink-bottle" effect: in analyzing MIP data, we assume that all pores are connected to the sample surface or a larger pore, and deviation from this assumption (so called "ink-bottle" pores) may lead to inaccurate interpretation of results. ${ }^{7}$ Thus the shape of the PSD obtained from gas adsorption measurements is more accurate at this range $(<10 \mathrm{~nm})$.
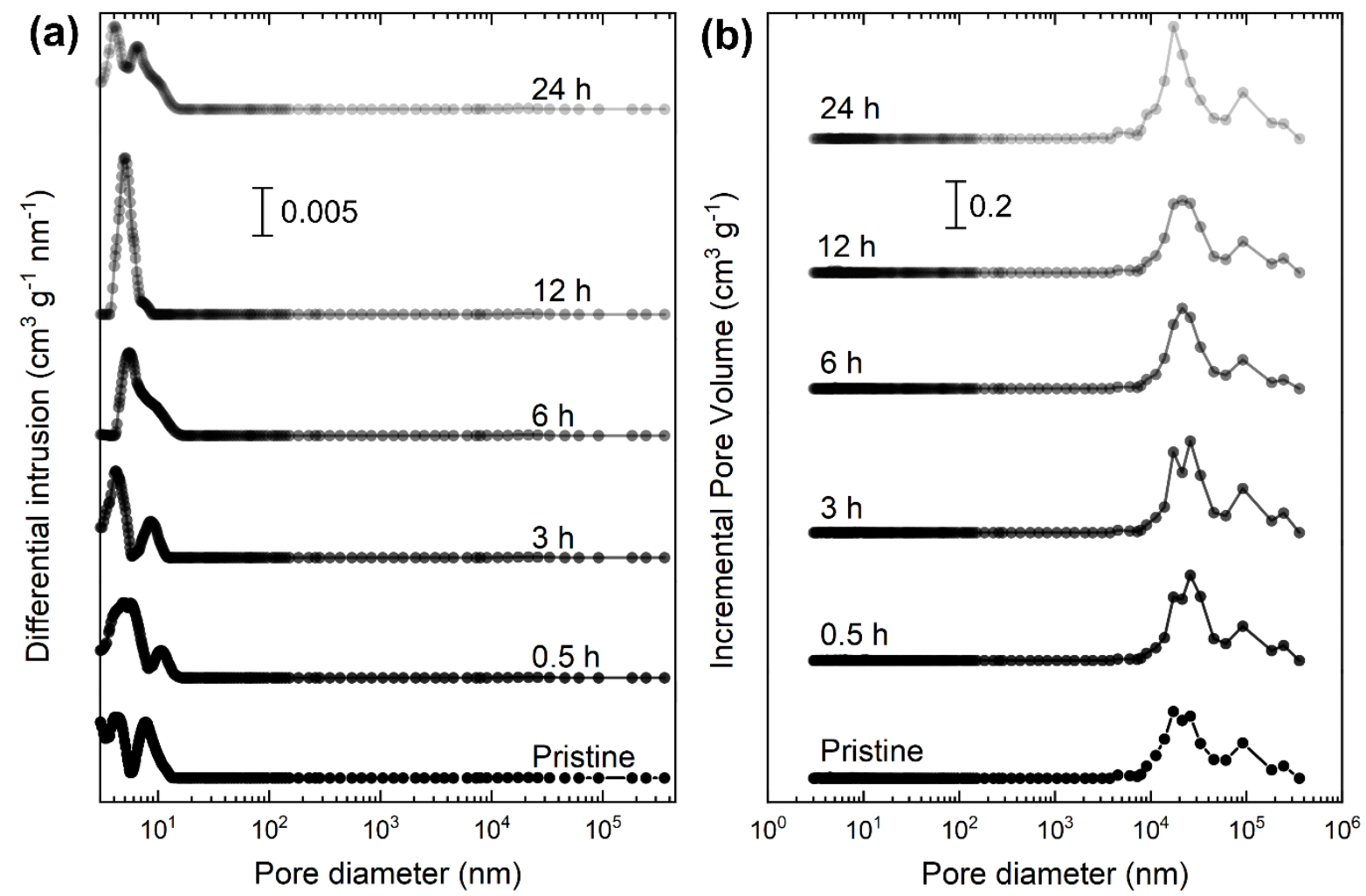

Figure S7 - PSD for electrodes treated at $450{ }^{\circ} \mathrm{C}$ from MIP. (a) Differential intrusion vs. pore diameter, (b) incremental pore volume vs. pore diameter. 


\section{S8. Visual representation of accessible pore diameter determination}

To estimate the maximum pore diameter accessible in different electrolytes, we compared the ECSA results with cumulative surface area obtained from BET as a function of pore diameter (Figure S8a). We find that in aqueous $1 \mathrm{M} \mathrm{H}_{2} \mathrm{SO}_{4}$, pores below $0.65 \mathrm{~nm}$ in size were not accessed in the $6 \mathrm{~h}$ sample, pores below $0.72 \mathrm{~nm}$ in size are not accessed in the $12 \mathrm{~h}$ sample, and pores below $0.85 \mathrm{~nm}$ in size are not accessed in the $24 \mathrm{~h}$ sample (Figure S8b). In $1 \mathrm{M} \mathrm{TEABF}_{4} /$ acetonitrile, we found that pores below $1.83 \mathrm{~nm}(6 \mathrm{~h}), 1.85 \mathrm{~nm}(12 \mathrm{~h})$, and $1.9 \mathrm{~nm}(24 \mathrm{~h})$ are not accessed (Figure S8c). 
Supporting Information
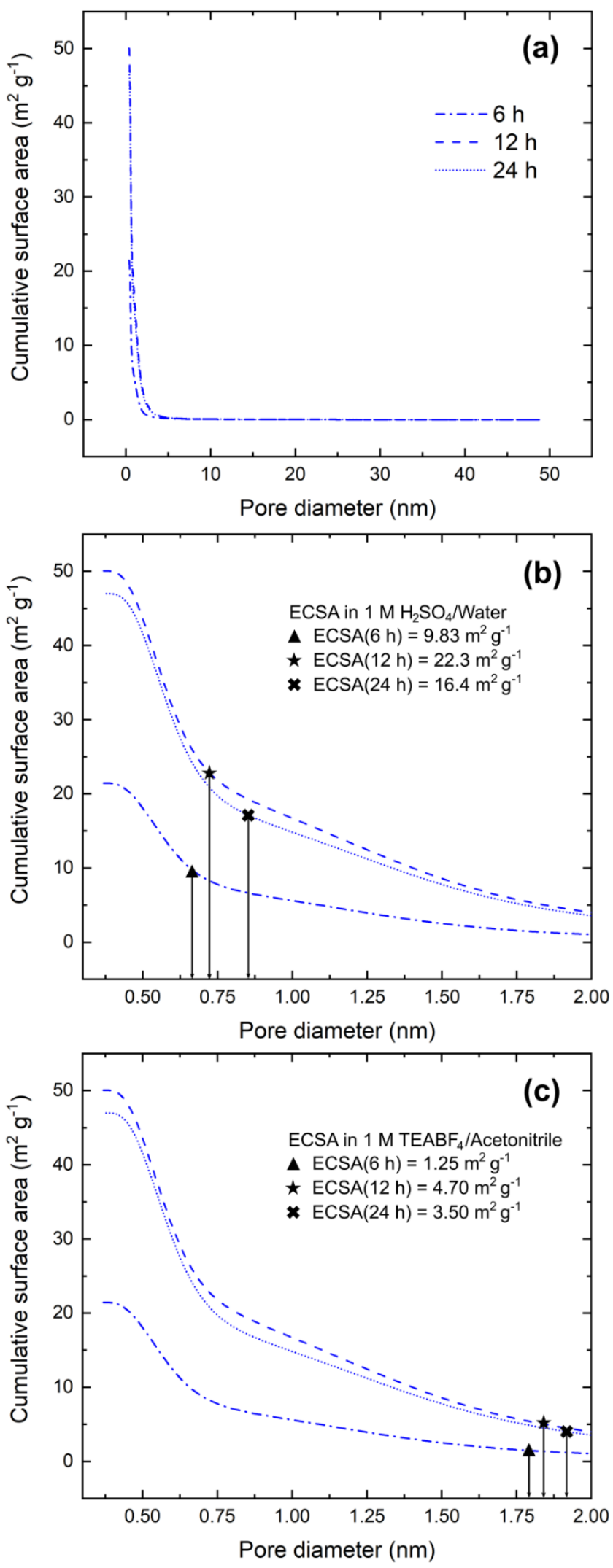
Figure S8 - Cumulative surface area measured with $\mathrm{Ar} / \mathrm{H}_{2}$ BET vs. pore diameter. (a) total cumulative surface area via range of measurable pore diameter. (b) Illustration of location of surface area measured with aqueous $\left(1 \mathrm{M} \mathrm{H}_{2} \mathrm{SO}_{4}\right)$ ECSA in relation to physical surface area, and corresponding "maximum" pore diameter that is accessible. (c) Location of surface area measured with nonaqueous $\left(1 \mathrm{M} \mathrm{TEABF}_{4}\right)$ ECSA in relation to physical surface area, and corresponding "maximum" pore diameter that is accessible.

\section{S9. References}

(1) Sun, C.-N. Hydrogen Evolution at the Negative Electrode of the All-Vanadium Redox Flow Batteries. Journal of Power Sources 2014, 248, 560-564. https://doi.org/10.1016/j.jpowsour.2013.09.125

(2) Forner-Cuenca, A.; Penn, E. E.; Oliveira, A. M.; Brushett, F. R. Exploring the Role of Electrode Microstructure on the Performance of Non-Aqueous Redox Flow Batteries. $J$. Electrochem. Soc. 2019, 166 (10), A2230-A2241. https://doi.org/10.1149/2.0611910jes.

(3) Darling, R. M.; Perry, M. L. The Influence of Electrode and Channel Configurations on Flow Battery Performance. J. Electrochem. Soc. 2014, 161 (9), A1381-A1387. https://doi.org/10.1149/2.0941409jes.

(4) Tenny, K. M.; Forner-Cuenca, A.; Chiang, Y.-M.; Brushett, F. R. Comparing Physical and Electrochemical Properties of Different Weave Patterns for Carbon Cloth Electrodes in Redox Flow Batteries. Journal of Electrochemical Energy Conversion and Storage 2020, 17 (4), 041108. https://doi.org/10.1115/1.4046661.

(5) Greco, K. V.; Forner-Cuenca, A.; Mularczyk, A.; Eller, J.; Brushett, F. R. Elucidating the Nuanced Effects of Thermal Pretreatment on Carbon Paper Electrodes for Vanadium Redox Flow Batteries. ACS Applied Materials \& Interfaces 2018, 10 (51), 44430-44442. https://doi.org/10.1021/acsami.8b15793.

(6) Maruyama, Y.; Nagamine, K.; Nomura, A.; Iwasa, S.; Tokito, S. Electrochemical Characterization of TEMPO Radical in Ionic Liquids. Electrochemistry 2020, 88 (1), 34 38. https://doi.org/10.5796/electrochemistry.19-00054.

(7) Moro, F.; Böhni, H. Ink-Bottle Effect in Mercury Intrusion Porosimetry of Cement-Based Materials. Journal of Colloid and Interface Science 2002, 246 (1), 135-149. https://doi.org/10.1006/jcis.2001.7962. 